\title{
Detection of diploid males and estimation of sex determination system in the parasitic wasp Diadegma semiclausum (Hellén) (Hymenoptera: Ichneumonidae) using an allozyme as a genetic marker
}

\author{
Takashi Noda \\ Tohoku National Agricultural Experiment Station, Morioka, Iwate 020-0198, Japan
}

(Received 16 August 1999; Accepted 15 November 1999)

\begin{abstract}
The presence of diploid males and a sex determination system in Diadegma semiclausum, a larval parasitoid of Plutella xylostella, was examined by using an allozyme as a genetic marker. Among six enzymes investigated, only phosphoglucomutase (PGM) was apparently polymorphic. Two discrete bands were detected on electrophoretic banding patterns of PGM, indicating PGM was a monomer with two alleles on one locus. After establishing pure lines of each PGM allele, the heterozygous females were allowed to mate with their sons to examine the occurrence rate of diploid males in their progenies. Thus the numbers of diploid males identified did not differ significantly from those expected from the single-locus complementary sex determination (CSD). Inbreeding and the subsequent emergence of diploid males could partly account for the male biased sex ratio in the laboratory culture of $D$. semiclausum.
\end{abstract}

Key words: Diadegma semiclausum, Plutella xylostella, sex determination, diploid male, allozyme variation

\section{INTRODUCTION}

Sex determination in Hymenopteran insects is of a haplodiploid type in which females are diploid, being produced from fertilized eggs, and males are haploid produced parthenogenetically from unfertilized eggs. However, the presence of diploid males has been reported in many wasp species since Whiting and Whiting (1925). Cross experiments have shown that diploid males may arise from fertilized eggs when mother wasp mates with a son. This phenomenon allows us to examine the sex determination system in Hymenoptera. Four types of model, i.e., complementary sex determination (CSD; Whiting, 1943), the genic balance model (Cunha and Kerr, 1957), the nucleo-cytoplasmic balance model (Crozier, 1971), and genomic imprinting sex determination (GISD; Poiré et al., 1993; Beukeboom, 1995), have been proposed for Hymenopteran sex determination. In Ichneumonidae, thus far only the single-locus CSD has been demonstrated (Stouthamer et al., 1992; Cook, 1993). In this CSD system, half of all fertilized eggs are expected to generate diploid males under the condition that the female mates with a son.
D. semiclausum (Hellén) is a solitary larval parasitoid of the diamondback moth Plutella xylostella (L.). This parasitoid was introduced to New Zealand from England to control $P$. xylostella in 1936 (Fitton and Walker, 1992), and thereafter introduced and released in many East Asian countries (Waterhouse, 1992). The performance of this parasitoid to control $P$. xylostella is thought to be high (Talekar and Yang, 1993). However, provided that the single-locus CSD is applied to D. semiclausum, the introduction of a small parasitoid population may result in frequent sibmating and a high proportion of diploid males. Also, male biased sex ratio of the parasitoid when reared at high temperature $\left(>30^{\circ} \mathrm{C}\right)$ has been reported (Yang et al., 1993), and this may obstruct their availability in the hot summer season. Thus, to consider why more males of $D$. semiclausum are produced in culture, it is important to clarify the sex determination system of the parasitoid. In this study, the author attempted to examine the presence of diploid males and to define the sex determination mechanism of $D$. semiclausum by using allozyme variation as a genetic marker. 


\section{MATERIALS AND METHODS}

Parasitoid and host. D. semiclausum used in this study were introduced from the Asian Vegetable Research and Development Center in Taiwan in 1989. A laboratory culture of $P$. xylostella was originated from a population collected in Mie Prefecture. Adults of $P$. xylostella were put in a glass jar $(7.5 \mathrm{~cm}$ in diam. $\times 13 \mathrm{~cm}$ in depth) with a paper lid on which they were allowed to deposit eggs. Eggs on the paper lid were collected 3 days after setting. Larvae were reared on radish sprout in a small plastic cup $(9 \times 5 \mathrm{~cm})$. To maintain the parasitoid culture, ca. 200 host larvae were presented to $10-15$ female parasitoids in a plastic container $(30 \times 20 \times 10 \mathrm{~cm})$ for one day. After parasitism females were removed and some fresh radish sprouts were supplied as food. Rearings were conducted under $20^{\circ} \mathrm{C}$, $16 \mathrm{~L}: 8 \mathrm{D}$ condition. Newly emerged adults were kept in a plastic container $(30 \times 20 \times 10 \mathrm{~cm})$ with $5 \%$ honey solution soaked in filter paper as food at $15^{\circ} \mathrm{C}, 16 \mathrm{~L}: 8 \mathrm{D}$. Unless otherwise indicated, 5- to 10-day-old parasitoid females and 3rd-stadium host larvae were used for experiments.

Genetic marker. To detect allozyme variation as a genetic marker, the following six enzymes were investigated using polyacrylamide gel electrophoresis (PAGE): alcohol dehydrogenase $(\mathrm{ADH}, \mathrm{EC}$ 1.1.1.1), esterase (EST), fumarase (FUM, EC 4.2.1.2), malic enzyme (ME, EC 1.1.1.40), glucosephosphate isomerase (GPI, EC 5.3.1.9), and phosphoglucomutase (PGM, EC 5.4.2.2). The electrophoresis was done by using native minislab gels $(75 \mathrm{~mm} \times 60 \mathrm{~mm}, 0.75$ $\mathrm{mm}$ in thickness; $7.5 \%$ polyacrylamide resolving gel and 3\% polyacrylamide stacking gel). The gels were stained following May (1992). Among the above mentioned enzymes, polymorphism in PGM was detected on electrophoretic banding patterns (Fig. 1A). A simple Mendelian inheritance pattern with allelic codominance was confirmed for the PGM locus (Noda, unpublished data). Pure lines with only S (PGM-S) or F (PGM-F) band were established by crossing for the subsequent experiments (Fig. 1B).

Cross experiment. The procedure for cross

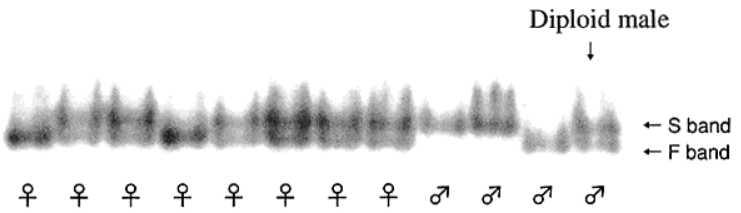

B

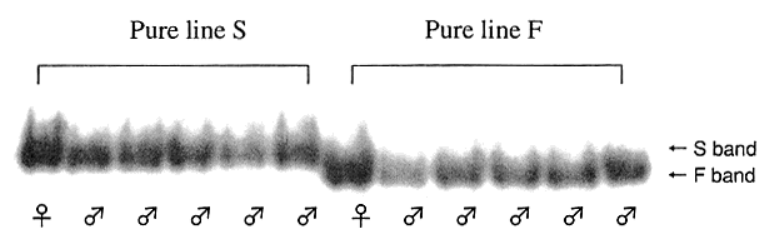

Fig. 1. Electrophoretic banding patterns of PGM in D. semiclausum. A: PGM phenotypes of individuals taken randomly from a culture; B: PGM phenotypes of pure lines.

experiments is demonstrated in Fig. 2. PGM-S females (Ps phenotype shown in Fig. 1, PsPS genotype) were paired with PGM-F males (Pf phenotype shown in Fig. 1, Pf genotype), then allowed to lay eggs into host larvae. Parasitized hosts were reared on radish sprout until parasitoid cocoons formed. These cocoons were kept separately until parasitoids emerged. All emerged $F_{1}$ females ought to be heterozygous (Pfs phenotype shown in Fig. 1, PfPs genotype). Six virgin $F_{1}$ females were allowed to lay eggs into 10-20 host larvae separately. Parasitized hosts were reared on radish sprout and one of the emerged males was paired with his mother in a small plastic cup. From 2 days after pairing, females were allowed to lay as many eggs as possible into host larvae every day until death. PGM phenotype of all offspring were checked by PAGE.

\section{RESULTS AND DISCUSSION}

Given that the sex determination of $D$. semiclausum follows the single-locus CSD, females ought to have 2 different sex alleles (Fig. 2). Therefore, sons must have one of the maternal sex alleles, and the sex ratio of diploid individuals from a mother-son crossing should be 1:1, assuming that their mortalities are the same. Considering PGM phenotype, combinations of PGM phenotype and sex of diploid individuals should be $\mathrm{Pfs}+$ : $\mathrm{Pf}$ or $\mathrm{Ps}+$ : $\mathrm{Pfs} \sigma^{7}: \mathrm{Pf}$ or 


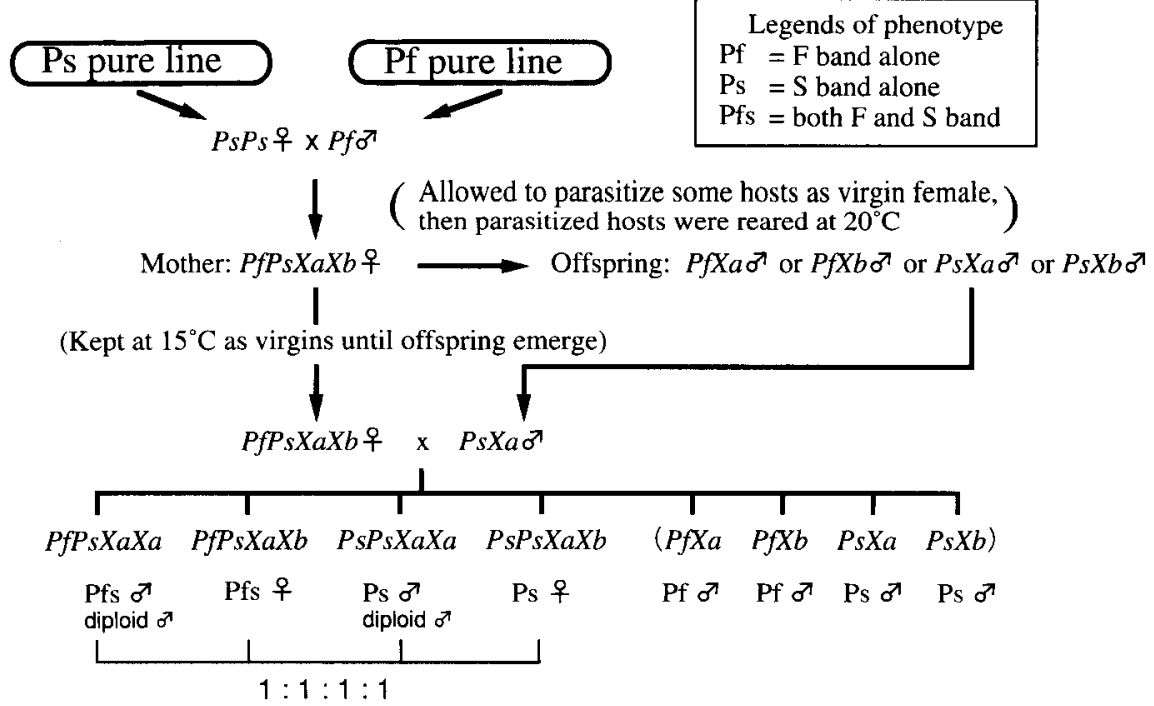

Fig. 2. The procedure of cross experiment to detect diploid males in D. semiclausum.

Table 1. Detection of diploid males of Diadegma semiclausum by allozyme variation of PGM

\begin{tabular}{|c|c|c|c|c|c|c|c|}
\hline \multirow{2}{*}{$\begin{array}{c}\text { Female } \\
\text { No. }\end{array}$} & \multirow{2}{*}{$\begin{array}{c}\text { No. of hosts } \\
\text { parasitized }\end{array}$} & \multirow{2}{*}{$\begin{array}{c}\% \\
\text { Pupation }\end{array}$} & \multicolumn{4}{|c|}{ No. of offspring with phenotype ${ }^{a}$} & \multirow{2}{*}{$\begin{array}{l}\text { Chi-square test } \\
\text { among phenotypes }\end{array}$} \\
\hline & & & FS 9 & F or $\mathrm{S}$ ? & FS o & $\mathrm{F}$ or $\mathrm{S}_{\sigma^{7}}^{b}$ & \\
\hline 1 & 116 & 56.9 & 3 & 3 & 9 & $(51)$ & $p>0.05\left(\chi^{2}=4.80\right)$ \\
\hline 2 & 147 & 81.6 & 21 & 10 & 19 & (70) & $p>0.05\left(\chi^{2}=4.12\right)$ \\
\hline 3 & 75 & 60.0 & 8 & 8 & 10 & (19) & $p>0.05\left(\chi^{2}=0.31\right)$ \\
\hline 4 & 53 & 56.6 & 6 & 3 & 3 & (18) & $p>0.05\left(\chi^{2}=1.50\right)$ \\
\hline 5 & 56 & 58.9 & 5 & 4 & 7 & (17) & $p>0.05\left(\chi^{2}=0.88\right)$ \\
\hline 6 & 74 & 71.6 & 8 & 9 & 7 & (29) & $p>0.05\left(\chi^{2}=0.25\right)$ \\
\hline
\end{tabular}

${ }^{\mathrm{a}} \mathrm{F}$ : $\mathrm{F}$ band alone, S: $\mathrm{S}$ band alone, FS: both $\mathrm{F}$ and $\mathrm{S}$ bands were detected.

${ }^{\mathrm{b}}$ Including diploid males of PGM homozygote.

${ }^{c}$ Test for goodness of fit with null hypothesis of FS $q: F$ or $\mathrm{S} \%:$ FS $\sigma^{r}=1: 1: 1$.

Ps $\sigma^{7}=1: 1: 1: 1$ according to Mendel's laws. Among these, the electrophoretic banding pattern of $\mathrm{Pf}$ and $\mathrm{Ps} \mathrm{O}^{\top}$ is indistinguishable from those of arrhenotokous males with $P f$ and $P S$ genotype. Accordingly, numbers of emerged individuals with phenotypes of $\mathrm{Pfs} q, \mathrm{Pf}$ or Ps $\&$, and Pfs o $\sigma^{7}$ were compared to the null hypothesis of $1: 1: 1$. The results showed that the null hypothesis could not be discarded in terms of a chi-square test (Table $1, p>0.05$ ). Therefore, it appears that the sex determination of $D$. semiclausum follows the single-locus CSD. The other three models, genic balance model, nucleo-cytoplasmic model, and genomic imprinting sex determination model demonstrated in Nasonia vitripennis (Dobson and Tanouye, 1998) can not account for the pres- ence of diploid males with the predicted ratio in mother-son crossings.

Single-locus CSD has been demonstrated in many wasp species. Cook (1993) reviewed sex determination in the Hymenoptera, and showed that single-locus CSD has occurred in at least 3 superfamilies, i.e., Apoidea, Vespoidea, and Ichneumonoidea. In Ichneumonoidea, for example, Speicher and Speicher (1940) reported the presence of diploid males in the braconid Bracon brevicornis and demonstrated a singlelocus CSD using recessive wing mutants. Hedderwick et al. (1985) demonstrated the occurrence of diploid males of the ichneumonid Diadromus pulchellus in an allozyme study and cytological analysis. Detection of singlelocus CSD in D. semiclausum strengthens the 
proposal that this system prevails in Ichneumonoidea.

Diploid males may suffer a higher mortality than diploid females and may be sterile. Petters and Mettus (1980) reported the decreased hatchability and possible early larval survival of diploid males in Bracon hebetor. Bostian (1934) reported that about $90 \%$ of diploid males that survived to adulthood were sterile in $B$. hebetor. Also in $D$. pulchellus, a great number of abnormal spermatozoa were observed in diploid males, and these spermatozoa with degenerative structures were probably not implicated in egg fertilization (Chauvin et al., 1988). In $D$. semiclausum, mortality in diploid males may not differ from that in diploid females, because the numbers of diploid males emerged were not significantly different from diploid females (Table 1). Since diploid males of $D$. semiclausum are not distinguishable by external characters, it is necessary to identify males' allozyme type to determine whether or not the diploid male is sterile. Sterility of the diploid male is the subject for a future study.

It is still unknown whether the male-biased sex ratio of $D$. semiclausum under high temperature conditions is due to an increase in diploid males. This would obstruct the availability of $D$. semiclausum in the hot season when $P$. xylostella population increases. Further study is needed to determine whether emergence of diploid males is affected by rearing temperatures.

\section{REFERENCES}

Beukeboom, L. W. (1995) Sex determination in Hymenoptera-a need for genetic and molecular studies. Bioesseys 17: 813817.

Bostian, C.H. (1934) Biparental males and biparental ratios in Habrobracon. Biol. Bull. 66: 166-181.

Chauvin, G., M. El Agoze, C. Hamon and J. Huignard (1988) Ultrastructure of the spermatozoids of haploid and diploid males of Diadromus pulchellus Wesmeal (Hymenoptera,
Ichneumonidae). Int. J. Insect Morphol. Embryol. 17: 359366.

Cook, J.M. (1993) Sex determination in the Hymenoptera: a review of models and evidence. Heredity 71 : 421-435.

Crozier, R. H. (1971) Heterozygousity and sex determination in haplodiploidy. Am. Natur. 105: 399-412.

Cunha, A. B. and W. E. Kerr (1957) A genetic theory to explain sex determination by arrhenotokous parthenogenesis. Forma Functio 1: 33-36.

Dobson, S. L. and M. A. Tanouye (1998) Evidence for a genomic imprinting sex determination mechanism in Nasonia vitripennis (Hymenoptera: Chalcidoidea). Genetics 149: 233242 .

Fitton, M. and A. Walker (1992) Hymenopterous parasitoids associated with diamondback moth: the taxonomic dilemma. In Diamondback Moth and Other Crucifer Pests: Proceedings of the Second International Workshop (N.S. Talekar ed.). Asian Vegetable Research and Development Center, Taipei, pp. 225-232.

Hedderwick, M.P., M. El Agoze, P. Garaud and G. Periquet (1985) Mise en évidence de mâles hétérozygotes chez l'hyménoptère Diadromus pulchellus (Ichneumonidae). Genet. Sel. Evol. 17: 303-310.

May, B. (1992) Stain recipes for specific enzymes. In Molecular Genetic Analysis of Populations (A. R. Hoelzel ed.). Oxford University Press, New York, pp. 271-280.

Petters, R. M. and R. V. Mettus (1980) Decreased diploid male viability in the parasitic wasp, Bracon hebetor. J. Heredity 71: 353-356.

Poiré, M., G. Périquet and L. Beukeboom (1993) The hymenopteran way of determining sex. Semin. Dev. Bio. 3: 357-361.

Speicher, B. R. and K. G. Speicher (1940) The occurrence of diploid males in Habrobracon brevicornis. Am. Natur. 74: 379-382.

Stouthamer, R., R. F. Luck and J. H. Werren (1992) Genetics of sex determination and the improvement of biological control using parasitoids. Environ. Entomol. 21: 427-435.

Talekar, N.S. and J.C. Yang (1993) Influence of crucifer cropping system on the parasitism of Plutella xylostella (Lep., Yponomeutidae) by Cotesia plutellae (Hym., Braconidae) and Diadegma semiclausum (Hym., Ichneumonidae). Entomophaga 38: 541-550.

Waterhouse, D.F. (1992) Biological control of diamondback moth in the Pacific. In Diamondback Moth and Other Crucifer Pests: Proceedings of the Second International Workshop (N. S. Talekar ed.). Asian Vegetable Research and Development Center, Taipei, pp. 213-224.

Whiting, P.W. (1943) Multiple alleles in complementary sex determination in Habrobracon. Genetics 28: 365-382.

Whiting, P.W. and A.R. Whiting (1925) Diploid males from fertilized eggs in Hymenoptera. Science 62: 437-438.

Yang, J. C., Y. I. Chu and N.S. Talekar (1993) Biological studies of Diadegma semiclausum (Hym., Ichneumonidae), a parasite of diamondback moth. Entomophaga 38: 579-586. 